Aletria, Belo Horizonte, v. 29, n. 3, p. 39-60, 2019

\title{
O retorno de Bartleby e a crise da interpretação alocrática
}

\section{The Return of Bartleby and the Crisis of Alocratic Interpretation}

\author{
Sérgio Luiz Bellei \\ Universidade Federal de Minas Gerais (UFMG), Belo Horizonte, Minas Gerais / Brasil \\ sergiobellei50@gmail.com
}

Resumo: Críticos e pensadores maiores da Era da Teoria (1965-1980) apresentaram como alternativa à prática hegemônica da intepretação o estudo de uma poética que, explicitando com rigor os mecanismos de produção do sentido, contribuiria para tornar mais precisa a atividade hermenêutica. Parcialmente descartados como pouco relevantes, esses estudos ofereceram, contudo, contribuições relativamente significativas para o desenvolvimento de novas formas de entendimento do texto literário não limitadas à prática interpretativa tradicional. A leitura que faz Agamben do conto Bartlety, $o$ escrevente, de Herman Melville, ilustra exemplarmente uma dessas novas formas de entendimento e os possíveis problemas delas decorrentes.

Palavras-chave: Hermenêutica; poética; interpretações alocráticas e autocráticas; Bartleby, o escrevente.

\begin{abstract}
Major critics and philosophers of the Age of Theory (1965-1980) developed as an alternative to the hegemonic practice of interpretation the study of a poetics that, by rigorously describing the mechanisms of meaning production, would contribute to make hermeneutic practices more precise. Partially discarded as of little relevance, these studies offered, nevertheless, relatively important contributions to the development of new forms of understanding literary texts not restricted to the traditional hermeneutic practice. Agamben's reading of Melville's tale, Bartleby, the Scrivener, forcefully illustrates one of these new forms of understanding and the possible problems related to it.
\end{abstract}

Keywords: Hermeneutics; poetics; alocratic and autocratic interpretations; Bartleby, the Scrivener. 


\section{Introdução: interpretar é preciso.}

Quando o livro de Jonathan Culler, The Pursuit of Signs (1981), foi republicado em 2001, acompanhou o texto um prefácio do autor dedicado a uma reflexão sobre os acontecimentos que marcaram os estudos literários nesse intervalo de vinte anos. A proposta do texto original era valorizar o campo de estudos ainda incipiente da semiótica como uma alternativa importante para enriquecer os estudos literários então dominados pela prática interpretativa. Não era o caso de substituir uma hermenêutica obcecada com a revelação do sentido do texto por uma poética capaz de explicitar os mecanismos de produção textual. O objetivo era aprimorar a prática interpretativa na medida em que ela fosse fundamentada em uma ciência capaz de explicitar com rigor como o sentido é produzido. No limite, o entendimento dos mecanismos da produção de sentido seria nada mais nada menos do que a condição de possibilidade da interpretação precisa, já que para que o sentido apareça é necessário conhecer "as regras e convenções, o sistema da significação que permite aos objetos culturais funcionarem como funcionam - ter os sentidos que têm para os membros de uma cultura". ${ }^{1}$ Esse programa de trabalho que ajudaria a entender como se produz uma interpretação, contudo, acabou não tendo sucesso porque foi entendido pelas práticas interpretativas hegemônicas como, "na melhor das hipóteses, um esforço pouco significativo para descobrir o óbvio, uma tentativa de explicitar o que em certa medida já era conhecido". ${ }^{2}$

No leque de propostas alternativas para o estudo literário que surgiu na Era da Teoria (1965-1980), ${ }^{3}$ a semiótica foi apenas um dos

\footnotetext{
1 “" [...] to construct an account of the rules and conventions, the system of signification, if you will, that enable cultural objects to function as they do - to have the meanings that they do for members of a culture" (CULLER. The Pursuit of Signs, p. v, tradução minha).

2 "It could be seen, at best, a rebarbative belaboring of the obvious, an attempt to make explicit what we at some level already know, and at worst an irrelevance" (CULLER. The Pursuit of Signs, p. xvii, tradução minha).

${ }^{3}$ Adoto aqui a periodização proposta por Terry Eagleton em After Theory. Eagleton considera esses quinze anos como o extraordinário período em que pensadores maiores escreveram trabalhos pioneiros: Jacques Lacan, Claude Lévi-Strauss, Louis Althusser, Roland Barthes, Michel Foucault, Raymond Williams, Pierre Bourdieu, Julia Kristeva, Jacques Derrida, Jurgen Habermas, Fredric Jameson, entre outros. "Muitas das ideias
} 
exemplos de derrota diante da prática interpretativa dominante. Um dos méritos maiores de The Pursuit of Signs é o esforço sistemático para demonstrar que a hegemonia das práticas interpretativas é de tal porte que acaba por neutralizar projetos alternativos com potencial para o desenvolvimento de uma poética (uma teoria do fazer poético, poien), transformando-os em incentivos para a intepretação. É o caso das teorias que voltaram sua atenção para a importância do leitor no processo do fazer poético. Culler dedica o capítulo "A Semiótica enquanto Teoria da Leitura" ao estudo das operações realizadas pelo leitor que, no ato interpretativo, deve reconhecer indicações textuais que configuram comportamentos de leitura. Certos textos, por exemplo, sinalizam para operações de gênero que podem excluir ou incluir a postura masculina ou feminina. Muito embora seja necessário evitar o equívoco de postular o leitor ideal, cada texto define, de formas diversas, um leitor que deve ser estudado em termos da utilização que faz de certos códigos e da exclusão de outros. No prefácio da edição de 2001, Culler observa que o interesse no estudo do leitor foi gradualmente substituído pelo interesse nas práticas interpretativas de "leitores, no plural", ${ }^{4}$ identificados em termos de gênero, sexualidade e etnia. $\mathrm{O}$ resultado foi um desvio de atenção: "avançamos das operações formais que caracterizam os atos interpretativos - estabelecer conexões, transformar o contrassenso em sentido figurado - para respostas a conteúdos particulares e para

desses pensadores têm ainda hoje valor incomparável. Algumas estão ainda motivando trabalhos de importância significativa" ("Many of the ideas of these thinkers remain of incomparable value. Some of them are still producing work of major importance") (EAGLETON. After Theory, p. 1). Representam também uma ruptura sem volta com a tradição de estudos literários: "Não há como voltar a uma época em que era suficiente proclamar que Keats é um deleite e que Milton é um espírito intrépido" "There can be no going back to an age when it was enough to pronounce Keats delectable or Milton a doughty spirit") (EAGLETON. After Theory, p. 1). O período historicamente concluído, permanece, contudo, indispensável no momento presente (2003). "Mas vivemos agora no momento posterior ao que se poderia chamar de alta teoria, um período que, enriquecido com as descobertas de pensadores como Althusser, Barthes e Derrida, avançou de certa forma para além deles" ("But we are living now in the aftermath of what one might call high theory, in an age which, having grown rich on the insights of thinkers like Althusser, Barthes and Derrida, has also in some ways moved beyond them") (EAGLETON. After Theory, p. 2, tradução minha).

4 "From reader to readers" (CULLER, The Pursuit of Signs, p. xxi, tradução minha). 
possibilidades de exclusão ou inclusão". ${ }^{5}$ Torna-se mais importante, por exemplo, interpretar o que o leitor homossexual, branco e do sexo masculino tem a dizer do que entender como ele é constituído formalmente enquanto leitor.

A força avassaladora da interpretação afetou também a desconstrução, muito possivelmente o movimento mais impactante da Era da Teoria. Culler observa certeiramente que, em geral, as leituras de textos realizadas por Derrida não constituem interpretações em seu sentido tradicional: "não se respeita a integridade do texto e não se procura por um princípio unificador que atribui a cada bloco de significado a sua função própria". ${ }^{6}$ Fiel a esses dois princípios, o intérprete tradicional produzia uma interpretação orgânica em que cada parte contribui para o sentido do todo. A leitura de Rousseau na Gramatologia substitui a perspectiva organicista por um procedimento que privilegia a lógica da suplementaridade, ou seja, aquela que governa o processo responsável por "um modelo idealizado de discurso ao atribuir certos aspectos problemáticos da linguagem à escrita para, em um segundo momento, isolar tais aspectos como secundários ou derivados". ${ }^{7}$ Longe de ser uma interpretação convencional, a leitura, nesse caso, aproxima-se de uma prática retórica que descreve uma operação textual:

Seria isso uma interpretação de Rousseau? Omite-se aqui a maior parte dos conteúdos de cada texto mencionado e não se identifica nenhuma unidade temática nos escritos de Rousseau. Derrida esforça-se, ao contrário, para descrever um processo geral que permite aos textos desconstruir

\footnotetext{
5 "We have moved [...] from formal operations of interpretation - making connections, transforming literal nonsense into figural sense - to responses to particular contents and to possibilities of inclusion or exclusion" (CULLER. The Pursuit of Signs, p. xx, tradução minha).

6 "There is no deference to the integrity of the text, no search for a unifying purpose that would assign each part its appropriate role" (CULLER. The Pursuit of Signs, p. 16 , tradução minha).

7 " [...] an idealized model of speech by attributing certain problematical features of language to writing and then setting writing aside as secondary and derivative" (CULLER. The Pursuit of Signs, p. 16, tradução minha).
} 
o sistema filosófico a que pertencem revelando a sua natureza retórica. ${ }^{8}$

A ênfase no viés retórico em Derrida sofre modificações quando a desconstrução chega à academia norte-americana. Em Blindness and Insight, Paul de Man sugere que Derrida teria conseguido apenas explicitar em Rousseau um processo de desconstrução já ativo no próprio texto, ou seja, faz uma leitura que mais interpreta do que aplica ao texto uma análise de natureza retórica. ${ }^{9}$ Mas é J. Hillis Miller que, posteriormente, transforma a proposta de de Man em um princípio metodológico básico de leitura em que qualquer texto não apenas contém em si mesmo o processo desconstrutivo, mas apresenta-se também como um discurso sobre a desconstrução. Manifestando sempre e necessariamente duas forças argumentativas contraditórias e em conflito, o texto gera uma indecidibilidade que "é sempre tematizada no próprio texto na forma de postulados metalinguísticos". É nesse contexto que Miller conclui que “as obras literárias maiores anteciparam de forma explícita a desconstrução realizada pelo crítico". ${ }^{10}$

Em The Pursuit of Signs, Culler demonstra que a tradição hermenêutica nos estudos literários preserva o seu poder hegemônico porque consegue, sem dificuldades maiores, neutralizar as propostas alternativas de poéticas voltadas para o fazer literário. Expressa, contudo, um certo otimismo quando sugere a possibilidade de um potencial de mudança em função do vigor e das repercussões vigorosas que surgiram da Era da Teoria. "A crescente influência da crítica europeia", diz Culler, "torna disponível uma variedade significativa de formas de entender a literatura, e se conseguirmos evitar que ela seja redirecionada para a área restrita da interpretação, a [...] crítica tornar-se-á tanto mais

\footnotetext{
8 "Is this an interpretation of Rousseau? It omits most of the contents of every text it mentions and fails to identify a thematic unity or a distinctive meaning for any of Rousseau's writings. Derrida is working, rather, to describe a general process through which texts undo the philosophical system to which they adhere by revealing its rhetorical nature" (CULLER. The Pursuit of Signs, p. 17, tradução minha).

${ }^{9}$ Ver DE MAN. Blindness and Insight, p. 102-141.

10 "It is also thematized in the text itself in the form of metalinguistic statements [...] The great works of literature [...] have anticipated explicitly any deconstruction the critic can achieve" (MILLER. Deconstructing the Deconstructers, p. 30-31, tradução minha).
} 
enriquecida". ${ }^{11}$ Um exemplo dessa variedade está no princípio da intertextualidade: "ler significa ler em relação a outros textos, em relação a códigos que constituem os produtos desses textos e que configuram uma cultura." $" 12$ A crítica dialética de Fredric Jameson, por exemplo, está menos interessada na interpretação de uma obra específica do que em uma "perspectiva histórica mais ampla, capaz de explicar por que uma dada interpretação se torna necessária"13 em dado momento histórico.

Beneficia-se também dos achados da Era da Teoria o trabalho de Hans Robert Jauss sobre os "horizontes de expectativa" que caracterizam uma época e que abrem espaço para o aparecimento de obras que atendem ao chamado de tais horizontes.

A Estética da Recepção não constitui uma forma de interpretar textos, mas antes uma tentativa de entender as mutações de sua inteligibilidade no tempo através da interpretação dos códigos e dos pressupostos interpretativos responsáveis pelo sentido que tais mutações têm para audiências diversas no fluxo temporal. ${ }^{14}$

Não se pode dizer que, nessas práticas alternativas do estudo da literatura, a intepretação desapareça. Mas a sua permanência modifica-se e já não tem o mesmo sentido e a mesma importância. O problema central desloca-se da intepretação em si para as suas condições de possibilidade.

No que se segue, um exemplo dessa mudança no sentido da intepretação será examinado em um texto que se tornou objeto de atenção de pensadores maiores da Era da Teoria. Trata-se do conto de Herman

11 "The increasing influence of European criticism is making available a greater variety of ways of writing about literature, and if we can refrain from redirecting them to the restricted task of interpretation, [...] criticism will be much the richer" (CULLER. The Pursuit of Signs, p. 11, tradução minha).

12 "To read is always to read in relation to other texts, in relation to the codes that are the products of these texts and go to make up a culture" (CULLER. The Pursuit of Signs, p. 13, tradução minha).

13 "[...] a broader historical account of why interpretation should be necessary" (CULLER. The Pursuit of Signs, p. 14, tradução minha).

14 "Rezeptions-ästhetik is not a way of interpreting works but an attempt to understand their changing intelligibility by identifying the codes and interpretive assumptions that give them meaning for different audiences at different periods" (CULLER. The Pursuit of Signs, p. 14, tradução minha). 
Melville, Bartleby, the Scrivener. Interpretações tradicionais do conto enfatizaram, quase unanimemente, a pergunta sobre a identidade de Bartleby. As leituras mais recentes, por outro lado, focalizaram a atenção no que Deleuze chamou de "a fórmula" (I prefer not to).${ }^{15}$ Essa mudança será aqui examinada em termos de uma passagem de interpretações alocráticas para interpretações autocráticas.

\section{Quem é Bartleby?}

Bartleby, the Scrivener: A Story of Wall Street (1851) dramatiza o encontro entre o narrador, proprietário de um escritório de advocacia em Wall Street, e Bartleby, que se apresenta para trabalhar como copista. Mas a relação entre empregador e empregado logo se complica quando o narrador chama a si a impossível missão de biografar um copista que, ao que tudo indica, não se enquadra no rol de pessoas que podem submeter sua vida a uma leitura ou a uma escrita. Essa dramatização inicial lembra um pouco o conto de um outro escritor norte-americano, Edgar Allan Poe, em "O Homem da Multidão" (The Man of the Crowd), já que aqui também um narrador sem nome persegue pelas ruas de Londres um estranho caminhante tentando, sem sucesso, entendê-lo e concluindo finalmente que se trata de alguém semelhante a um livro "que não se deixa ler" ${ }^{16}$ Bartleby não é apenas um operário procurando emprego em Wall Street. Como no caso do caminhante no conto de Poe, o copista é, principalmente, alguém que "não se deixa ler". E a grafia da vida de Bartleby é impossível porque dele nada ou quase nada se sabe:

Bartleby era um desses seres acerca dos quais nenhuma informação é precisa, exceção feita ao que dispomos de fontes documentais - estas, no entanto, raríssimas. O que meus olhos perplexos viram de Bartleby - eis tudo que sei a seu respeito, descontado, é preciso dizer, um estranho rumor, do qual me ocuparei a seu tempo. ${ }^{17}$

O início do conto anuncia, portanto, o fracasso de uma narrativa. $\mathrm{Ou}$, dizendo de outro modo, anuncia o fracasso de um biógrafo que

\footnotetext{
${ }^{15}$ DELEUZE. Crítica e clínica, p. 80.

${ }^{16}$ POE. The Man of the Crowd, p. 506.

${ }^{17}$ MELVILLE. Bartleby, o Escrevente, p. 12.
} 
narra sua própria impotência para concluir sua narrativa biográfica. Mas o narrador descarta a opção lógica de se silenciar diante da tarefa impossível. A escolha faz sentido porque não agrada ao narrador produzir relatos de fácil composição, ou seja, biografar o que conhece e que teria como resultado agradar tanto leitores bem-humorados como sentimentais. Seu desejo é contar histórias misteriosas, difíceis de serem narradas e que, aparentemente, não seriam do agrado de leitores comuns. Note-se que o próprio narrador exemplifica a diferença entre os dois tipos de narrativa quando apresenta ao leitor os dois outros copistas do escritório e o office boy. Podem ser identificados e compreendidos imediatamente, não tanto pelos nomes próprios, mas por seus apelidos, que de saída apontam para "o seu caráter e personalidade". ${ }^{18}$ Turkey é um inglês de cerca de sessenta anos, sóbrio e bem-humorado na parte da manhã, afetado pela bebida e mal-humorado na parte da tarde. Nippers, por outro lado, é um jovem de vinte e cinco anos que, sofrendo de indigestão na parte da manhã, mostra-se nervoso e irritadiço. Na parte da tarde, comporta-se bem e trabalha assiduamente. Ginger Nuts, o office boy, é um jovem de doze anos que se alimenta principalmente de amêndoas (nuts) e tem como uma de suas funções trazer para Turkey e Nippers maçãs e o tipo de bolo conhecido como ginger nut (bolinho de gengibre). O narrador expande essa caracterização sumária com uma variedade de detalhes. $\mathrm{O}$ rosto de Turkey, por exemplo, altera-se a partir do meio-dia: exibindo "belos tons rosados" na parte da manhã, transforma-se em um "braseiro natalino" à tarde; e a mudança ocorria dia após dia, "com regularidade e glória preservadas". ${ }^{19}$ A indigestão de Nippers, por outro lado, tornase sempre perceptível "por sua irritabilidade, seu sorriso nervoso, pelo ranger dos dentes, [...] pelo praguejar desnecessário". ${ }^{20}$

A tipicidade que define Turkey e Nippers não deixa de estar presente também no narrador, o que o torna capaz de escrever sua própria biografia com precisão:

Sou um homem que, já na juventude, imbuiu-se da profunda convicção de que, no tocante à vida, o caminho mais fácil é também o melhor. [...] Sou daquele tipo de advogado que não conhece ambição, jamais se dirige a

\footnotetext{
${ }^{18}$ MELVILLE. Bartleby, o Escrevente, p. 15.

${ }^{19}$ MELVILLE. Bartleby, o Escrevente, p. 15.

${ }^{20}$ MELVILLE, Bartleby, o Escrevente, p. 18.
} 
um júri e, de maneira geral, recusa-se ao reconhecimento público; mas que, na tranquilidade vicejante de um sossegado retiro, dedica-se a aprazíveis títulos e hipotecas e propriedades de gente abastada. Todos que me conhecem consideram-me um homem, acima de tudo, prevenido (safe). O já falecido John Jacob Astor [...] não hesitou em apontar a prudência como minha grande qualidade; logo atrás estava o método. ${ }^{21}$

O caricaturesco não está aqui tão próximo das representações de Turkey e Nippers, mas também não está tão distante: Jacob Astor reconhece no advogado o traço dominante (prudência) que, não por acaso, corresponde à noção de "prevenido" proposta na breve autobiografia.

As leituras tradicionais do conto assumiram, quase unanimemente, essa situação de um narrador diante de um mistério de difícil ou impossível revelação, mas que deve, mesmo assim, tentar interpretá-lo. O intérprete está aqui diante do que Forster denominou, há quase um século, um personagem "esférico" (round), ou seja, aquele que desafia o leitor porque representa a "incalculabilidade da vida" nas páginas de um livro, em contraste com personagens planos (flat), que representam uma única idéia e são "facilmente reconhecidos quando aparecem". ${ }^{22} \mathrm{Na}$ realidade, não seria descabido afirmar que o intérprete tradicional imita, com frequência, as tentativas de leitura do narrador, que se serve do vasto repertório de lógicas explicativas que o momento histórico lhe oferece: a lógica da caridade cristã; a lógica de um trabalhador em Wall Street; o pressuposto da predestinação, que definiria como uma das missões de sua vida cuidar de Bartleby; a lógica das pressuposições, que o autorizaria a acreditar que, tendo atuado como patrão e despedido Bartleby, o escrevente deixaria o escritório; a caracterização do comportamento de Bartleby como típico de um doente mental; a decisão de mudar-se para um outro escritório; a reconstituição histórica do passado do escrevente.

Todas as tentativas fracassam e o conto termina sem uma resposta definitiva. $\mathrm{O}$ escrevente revela-se, no final das contas, como alguém que não escreve e não explica ou, mais precisamente, prefere

${ }^{21}$ MELVILLE, Bartleby, o Escrevente, p. 12.

22 "One great advantage of flat characters is that they are easily recognized whenever they come in. [...] (A round character) has the incalculability of life about it - life within the pages of a book" (FORSTER. Aspects of the Novel, p. 103-105, 118, tradução minha). 
não explicar. Instala-se no centro do conto um vazio e um mistério que perturbam não apenas o narrador, como os demais empregados do escritório e o leitor. Perturbam também toda a crítica literária posterior, que tem como missão primária revelar os segredos ocultos no texto e, até mesmo, os que explicitamente apresentam-se como irreveláveis. Bastaria um rápido olhar para a fortuna crítica tradicional de Bartleby para perceber que boa parte das hipóteses interpretativas são análogas às tentativas do narrador de, sem sucesso, atribuir um significado ao escrevente. Na contextualização cristã, Bartleby poderia ser visto como uma representação do próprio Cristo; na de Wall Street, um operário vitimizado pelo capital; estigmatizado como doente mental, poderia ser caracterizado, mais especificamente, como esquizofrênico ou autista.

Essas interpretações obedecem a certos princípios gerais que já foram esquematicamente sugeridos anteriormente: partem do pressuposto de que o conto, como qualquer texto literário, é um todo orgânico em que é possível perceber, no ato de leitura, um princípio unificador em que cada bloco de significado tem uma função própria que contribui para o entendimento do todo. Mas como esse princípio unificador não é - ou não é apenas - ontológico (vale dizer, inerente ao texto), mas também epistemológico (ou seja, depende também da intervenção cognitiva do leitor), as interpretações devem necessariamente proliferar e competir entre si, não em termos de um critério de verdadeiro ou falso, mas de maior ou menor validade. Em texto de 1963, após afirmar que a tarefa da crítica "não é absolutamente descobrir 'verdades' mas somente "validades",, Roland Barthes sugere um possível critério de validade que pode ser aplicado a grande parte da interpretação tradicional: "seu papel é unicamente elaborar ela mesma uma linguagem cuja coerência, cuja lógica, e para dizer tudo, cuja sistemática possa recolher, ou melhor ainda 'integrar' [...] a maior quantidade de linguagem do texto a ser trabalhado". ${ }^{23}$ A tarefa da crítica, Barthes conclui,

[...] não consiste em "descobrir", na obra ou no autor observados, alguma coisa de "escondido", de "profundo", de "secreto", que teria passado despercebida até então (por que milagre? Somos nós mais perspicazes do que nossos predecessores?), mas somente ajustar, como um bom marceneiro que aproxima apalpando "inteligentemente"

${ }^{23}$ BARTHES. O que é a crítica?, p. 161. 
duas peças de um móvel complicado, a linguagem que lhe fornece sua época (existencialismo, marxismo, psicanálise) à linguagem, isto é, ao sistema formal de constrangimentos lógicos elaborados pelo próprio autor segundo sua própria época. [...] A "prova" da crítica, se ela existe, depende de uma aptidão não para descobrir a obra interrogada, mas ao contrário para cobri-la o mais completamente possível com sua própria linguagem. ${ }^{24}$

O narrador do conto de Melville é um crítico ou intérprete barthesiano avant la letre: tenta, mas sem sucesso, interpretar Bartleby com a ajuda dos sistemas que lhe fornece a sua época. É o que faz também a crítica tradicional de Bartleby, mas utilizando as metalinguagens mais sofisticadas que lhe oferece uma época posterior. É o caso, por exemplo, da clássica leitura feita por Leo Marx em 1953. Como todo ato interpretativo, a leitura de Marx começa com um olhar seletivo que isola um bloco de significado textual a ser privilegiado em relação aos demais. Essa escolha, que implica necessariamente uma postura valorativa e política, obedece de forma geral a dinâmica paradoxal de revelação e ocultamento (blindness and insight) como definida por Paul de Man. A leitura de um texto é sempre acompanhada de um ponto cego que não é percebido pelo crítico porque a sua percepção é configurada pela força de seu horizonte de expectativa (crenças, leituras, inclinações políticas...). Como consequência, escolhe para análise alguns detalhes, o que o impede de atentar para outros. A dinâmica é paradoxal porque a cegueira, longe de poder ser evitada ou recuperada no momento da leitura, é a própria condição de possibilidade da visada interpretativa. Há um preço a pagar pelo olhar que ilumina (insight) e esse preço é, precisamente, a escuridão que acompanha a cegueira. O insight "permanece sempre oculto no interior [da cegueira], como o sol está oculto na sombra, ou a verdade no erro". 25

O olhar seletivo de Marx isola, no conto de Melville, o bloco de significado dedicado à temática de um copista de Wall Street que, tendo copiado assiduamente os documentos legais nos primeiros dias após

\footnotetext{
${ }^{24}$ BARTHES. O que é a crítica?, p. 161-162, grifos do autor.

25 "the one [the insight] always lay hidden within the other [the blindness] as the sun lie hidden within a shadow, or truth within error" (DE MAN. Blindness and Insight, p. 103, tradução minha).
} 
sua contratação, resolve não mais conferir as cópias produzidas com os originais e, finalmente, não mais copiar coisa alguma. Esse bloco de significado, por sua vez, é examinado à luz de um dos códigos ou sistemas de significados disponíveis no momento histórico, ou seja, a biografia do autor em seu contexto histórico. Marx estabelece cuidadosamente um paralelo entre o copista que não mais copia e o escritor Melville que, em carta a Hawthorne datada de 1851, manifesta sua decisão de não mais escrever o tipo de best-seller que tematizava viagens a lugares exóticos e que o fizera famoso em anos anteriores (Typee, de 1846; Omoo, de 1847) para dedicar-se a romances voltados para temas filosóficos (Moby Dick) e que não eram do agrado do grande público norte-americano. Há, para Marx, uma analogia entre o copista isolado e emparedado em Wall Street e o escritor em Nova York porque são ambos vitimizados por um contexto socioeconômico e cultural que não valoriza a prática escrita original e criativa. Bartleby recusa-se a copiar textos mecanicamente, Melville decide não mais imitar formas ficcionais, também mecânicas, de agrado popular. Note-se que o próprio narrador, como sugere o breve resumo do conto apresentado acima, tematiza a questão quando se apresenta como um biógrafo que se recusa a atender ao apelo do gosto popular e dedicar-se à produção de narrativas difíceis ou impossíveis de serem escritas. E é também o narrador que alerta o leitor para a diferença entre a cópia mecânica e monótona e a literatura maior. Copiar é "tarefa aborrecida, tediosa, letárgica", e seria difícil imaginar "que o intrépido poeta Byron tivesse se sentado de bom grado com Bartleby para examinar um documento legal de [...] quinhentas páginas" ${ }^{26} \mathrm{O}$ modo de produção capitalista já visível na Wall Street de meados do século XIX, contudo, favorece justamente um mercado de cópias e imitações para consumo fácil e imediato. E Wall Street não é apenas, nesse momento histórico, um local isolado para o exercício da lógica do capital. É também um emblema da própria América. É assim que a entendem, na leitura de Marx, tanto Melville como Bartleby. Para ambos, Wall Street era a América.

No contexto do presente ensaio, importa, sobretudo, destacar na leitura de Marx a estratégia discursiva para validar o insight interpretativo na forma como a definiu Barthes. Marx não poupa esforços para produzir uma linguagem cuja "lógica" e "coerência" tornem possível "integrar [...] a

${ }^{26}$ MELVILLE. Bartleby, o Escrevente, p. 26. 
maior quantidade de linguagem" 27 do texto de Melville. Consegue, assim, "cobrir" o texto original "o mais completamente possível". ${ }^{28} \mathrm{O}$ exemplo maior dessa força integrativa, já enunciado no título do ensaio (Melville's Parable of the Walls), encontra-se no cuidadoso mapeamento da temática dos muros, entendida como a figura dominante no conto. Desde que se instala no escritório até o momento de sua morte na prisão, Bartleby está não apenas isolado entre paredes, mas por vezes por elas obcecado. No escritório, Bartleby ocupa uma escrivaninha próxima a uma janela que lhe permite apenas ver o muro do prédio vizinho. Seu local de trabalho é também isolado das demais dependências do escritório por um biombo verde de telas altas que permite que o copista seja ouvido, mas não visto, por seu patrão. Não surpreende, portanto, que o próprio narrador descreva o ambiente de trabalho como sendo "carente do que os paisagistas chamam de "vida" ${ }^{29}$ E é nesse ambiente que, após interromper o trabalho de copiar, Bartleby passa seus dias de olhos fixos no muro exterior.

Quando Bartleby, recusando-se a deixar o escritório já abandonado pelo advogado, é finalmente levado à força para a prisão, a trajetória é a de quem se desloca de um emparedamento para outro. Apropriadamente chamada de The Tombs (As Tumbas), a prisão é literalmente o túmulo do copista. Em sua última visita ao ex-funcionário na prisão, o narrador deparase com seu corpo inerte no pátio, "estranhamente encolhido ao pé do muro - os joelhos dobrados para cima, o tronco de lado, a cabeça sobre a pedra fria". ${ }^{30}$ É esse o destino daqueles que se rebelam contra a lógica capitalista de Wall Street. Marx mapeia cuidadosamente a progressão da rebeldia de Bartleby: a recusa de produzir cópias mecanicamente, a resistência a toda e qualquer autoridade e, finalmente, a ameaça ao próprio direito sagrado à propriedade privada. Este último é comprometido quando o advogado, percebendo-se impotente para despedir Bartleby, resolve mudar-se para um outro local de trabalho, permitindo ao copista permanecer no local que acabou por transformar-se em sua única moradia. Marx comenta:

Agora, mais claramente do que antes, o advogado percebe que Bartleby ameaça o próprio direito sagrado da propriedade, pois o copista insubordinado no final

\footnotetext{
${ }^{27}$ BARTHES. O que é a crítica?, p. 162.

${ }^{28}$ BARTHES. O que é a crítica?, p. 162.

${ }^{29}$ MELVILLE. Bartleby, o Escrevente, p. 14, 25.

${ }^{30}$ MELVILLE. Bartleby, o Escrevente, p. 77.
} 
das contas poderia viver mais do que ele próprio e assim "exigir a posse [...] [do imóvel] alegando o direito de ocupação perpétua". Se isso acontecesse, a lógica pouco ortodoxa de Bartleby, e não a vontade do advogado, dominaria o mundo de Wall Street. ${ }^{31}$

A leitura de Marx ilustra vigorosamente o que E. D. Hirsch chama de intepretação "alocrática" (ő $\lambda \lambda \mathrm{o} \varsigma$, outro), ou seja, aquela em que a escolha de uma chave de leitura (cypher key) é orientada "para a reconstrução de um evento histórico de outra pessoa ou comunidade". ${ }^{32}$ Existe, nesse caso, a crença de que um evento histórico pode ser estudado e conhecido, muito embora esse conhecimento possa conter erros ou omissões a serem posteriormente corrigidas ou completadas. É por esse motivo que o termo "reconstrução" deve ser aqui enfatizado. Como qualquer evento histórico só é acessível em forma de narrativa ou narrativas, e como essas narrativas podem sempre ser corrigidas, atualizadas ou alteradas, toda interpretação alocrática nelas fundamentada deve também submeter-se a revisões. A leitura de Marx fundamenta-se em uma norma alocrática porque recorre à reconstrução do significado histórico de Wall Street em meados do século XIX e, paralelamente, à reconstrução biográfica de Herman Melville nesse mesmo período. E serve-se dessas reconstruções para, com sucesso, "cobrir" a textura do conto tão completamente quanto possível, o que lhe garante uma sobrevida de valor até o momento presente. Robert T. Tally, por exemplo, retornou recentemente ao ensaio de Leo Marx para, de um lado, reconhecer o mérito da metáfora do muro e, de outro, apontar para suas limitações. Não é suficiente, para Tally, entender Bartleby como uma representação do escritor que se recusa a "produzir literatura pobre para uma sociedade que não aceita a literatura maior" ${ }^{33}$ É preciso ir além e pensá-lo em

31 "Now, more clearly as before, the lawyer is aware that Bartleby jeopardizes the sacred right of private property itself, for the insubordinate writer in the end my 'outlive' him and so "claim possession [of his office] by right of perpetual occupancy. If this happens, of course, Bartleby's unorthodox assumptions rather than the lawyer's will eventually dominate the world of Wall Street" (MARX. Melville's Parable of the Walls, p. 615, tradução minha).

32 "[...] to the reconstructed historical act of another person or community" (HIRSCH. The Politics of Theories of Interpretation, p. 241, tradução minha).

33 "Bartleby embodies Melville's refusal as a writer to produce bad literature for a society that will not accept good literature" (TALLY. Reading the Original: Alienation, 
termos de uma alienação radical que acaba por isolá-lo da sociedade, dos companheiros de trabalho, dos comportamentos convencionais e, em sua insistência para usar a expressão "I prefer not to", da própria linguagem. É essa alienação absoluta que faz de Bartleby alguém "que não pode ser conhecido". ${ }^{34}$

À interpretação alocrática Hirsch contrapõe uma outra, a que chama de "autocrática". Pratica a leitura autocrática aquele que, na escolha do código-chave, leva em conta apenas "o de sua preferência, ou o que lhe parece certo, ou o que lhe foi dado desde sempre". A autoridade da prática de leitura não é transferida para um outro contexto (aquele de uma reconstrução histórica, por exemplo), mas é atribuída tão somente ao próprio intérprete. $E$ trata-se de leitura que não é, em princípio, sujeita a revisões, a menos que o intérprete venha a optar por uma chave de leitura alternativa. "A norma autocrática", diz Hirsch, "é a priori e não pode ser corrigida; a norma alocrática é a posteriori e passível de revisão". 35 Hirsch lembra que, tratando-se nos dois casos de uma escolha feita pelo leitor, a opção por uma ou outra norma é de natureza política e não epistemológica, ou seja, a validade de conhecimento está ou pode estar presente em ambas sem que isso isente o intérprete de uma preferência fundamentada em questões éticas. Epistemologicamente válidas, uma ou outra prática interpretativa pode ser, contudo, mais eticamente justificável em uma dada situação histórica.

Interpretações autocráticas ganharam fôlego na Era da Teoria e privilegiaram, para a prática de leitura, o texto de Melville. Em livro publicado em 2011, Gisèle Berkman documentou exaustivamente o interesse obsessivo de representantes maiores da filosofia europeia entre o início da década de setenta e o final da de oitenta.

De Blanchot a Derrida, passando por Badiou, Zizec e Negri, um certo número de pensadores e filósofos apropriaram-se do enigma de Bartleby, transformando-o

\footnotetext{
Writing, and Labor in "Bartleby, the Scrivener", p. 8, tradução minha).

34 "Bartleby's alienation makes him profoundly unknowable and unreadable" (TALLY. Reading the Original: Alienation, Writing, and Labor in "Bartleby, the Scrivener", p. 9 , tradução minha).

35 "The autocratic norm is a priori and incorrigible; the allocratic norm is a posteriori and revisable" (HIRSCH. The Politics of Theories of Interpretation, p. 242, tradução minha).
} 
no emblema de como a literatura, sereia que é, seduz e aprisiona a filosofia. ${ }^{36}$

A esses nomes é preciso acrescentar o de Agamben, que escreve sobre Bartleby depois da Era da Teoria, mas que mantém estreita ligação com pensadores maiores do período. Em todos os casos, o interesse extraordinário de representantes maiores do pensamento filosófico pelo conto de Melville clama por elucidações. Para Berkman, um possível motivo para tal interesse encontra-se no conceito foucaultiano do "pensamento do exterior" (la pensée du dehors), ou seja, o pensamento voltado para o resto discursivo que, subjacente a toda enunciação, não tem limites e escapa a qualquer tentativa de entendimento totalizante. De formas diversas, tal conceito está presente na obra de pensadores como Derrida, Deleuze e Agamben. Na literatura, representam de forma exemplar o pensamento do exterior escritores como "Melville e Kafka, [...] na medida em que seus textos oferecem uma resistência infinita e que não encontra resposta no círculo hermenêutico da pergunta e da resposta". ${ }^{37}$ São, portanto, resistentes a toda e qualquer tentativa de intepretação, inclusive ao tipo de intepretação que Hirsch chama de alocrática. O problema é que, quando os filósofos associados à Era da Teoria descartam a interpretação alocrática, torna-se inevitável um deslize politicamente problemático para a prática autocrática.

\section{Bartleby \& Cia.}

Ainda que visível em leituras como as de Derrida e Deleuze, é, contudo, nas leituras de Bartleby feitas por Agamben que a prática autocrática se revela de forma exemplar. Em La Comunità che viene (1990), há um breve capítulo dedicado ao conto de Melville que é

\footnotetext{
36 "De Blanchot à Deleuze, puis à Derrida - mais il faudrait citer également [...] Agamben, Badiou, Zizek et Negri -, um certain nombre de penseurs et de philosophes se sont emparés de l'énigme de Bartleby, devenue embleme de ce par quoi la littérature, cette sirene, saisit et séduit la philosophie" (BERKMAN. L'Effet Bartleby: Philosophes Lecteurs, p. 15, tradução minha).

37 “À ce égard, Melville, Kafka, étaient les auteurs idéaux, dans la mesure où leurs textes offraient une résistance infinie, non soluble dans le cercle herméneutique de la question et de la réponse" (BERKMAN. L'Effet Bartleby: Philosophes Lecteurs, p. 23, tradução minha).
} 
ampliado em ensaio publicado em 1993 sob o título de Bartleby o dela Contingenza. Nos dois casos, o texto de Agamben ignora completamente questões normalmente relevantes para a interpretação alocrática, sejam elas filológicas, literárias ou biográficas. Nenhuma relevância é atribuída a possíveis semelhanças do conto com textos anteriores de Poe ou de Dickens, ou à possível semelhança do protagonista com o próprio Melville ou com algum de seus contemporâneos. E não há nos textos nenhuma menção explícita a Wall Street, apesar da referência feita no ensaio de 1993 a um law-copyist que deve ser entendido não apenas em sua relação com o advogado no momento em que a história ocorre, mas também no "sentido evangélico" ("the letter killeth, but the spirit giveth life" $)^{38} \mathrm{em}$ que "o renunciar à cópia é também um renunciar à Lei, um liberar-se da "antiguidade da letra" ${ }^{39}$ Para o leitor habituado à prática da interpretação alocrática, Agamben passa a impressão de não ter nenhum interesse no conto de Melville como um todo orgânico. O primeiro ensaio inclui apenas, na conclusão do texto, uma breve referência a Bartleby. $\mathrm{O}$ escrevente representa o anjo da tradição árabe chamado de "Qalam, ou seja, Pena, e cujo lugar é uma potência imperscrutável".${ }^{40} \mathrm{E}$ porque "não cessa simplesmente de escrever, mas 'prefere não', é a figura extrema desse anjo, que não escreve nada além da sua potência de escrever". ${ }^{41}$ As páginas restantes do texto são dedicadas à explicitação do significado filosófico dessa potência. No volume como um todo, tanto o anjo quanto Bartleby são apenas exemplos de uma comunidade que está por vir, constituída por singularidades que, existindo apenas em um estado daquela potência pura anterior ao ato que dela resulta e que é, ao mesmo tempo, potência de ser e não ser ou de realizar-se ou não, recusam-se a participar de toda e qualquer categoria de pertença. A estrutura do ensaio de 1993 é semelhante: uma longa reflexão sobre a potência, agora em termos do conceito de contingentia absoluta, precede uma leitura de Bartleby enquanto exemplo maior da teoria. Mas o argumento é aqui expandido tanto no caso da

\footnotetext{
${ }^{38}$ AGAMBEN. Bartleby, ou da Contingência, p. 51

${ }^{39}$ AGAMBEN. Bartleby, ou da Contingência, p. 51.

40 "Qalam, Penna, il cui luogo è uma potenza imperscrutabile" (AGAMBEN. La comunità che viene, p. 27, tradução minha).

41 'non cessa semplicemente di scrivere, ma 'preferisce di no', è la figura estrema di quest'angelo, che non scrive nient'altro che la sua potenza di non scrivere" (AGAMBEN. La comunità che viene, p. 27, tradução minha).
} 
reflexão sobre a potência como no caso da leitura do escrevente. Escreve Agamben sobre a contingentia: "Um ser que pode ser e, ao mesmo tempo, não ser, chama-se, em filosofia primeira, contingente. $\mathrm{O}$ experimento, em que Bartleby se arrisca, é um experimento de contingentia absoluta" ${ }^{42}$

Repetindo seguidamente a fórmula "prefiro não" (I prefer not to), que nem afirma e nem nega, Bartleby isola-se em uma suspensão de sentido que, sendo pura potência, que não é jamais resolvida em um ato afirmativo, resiste a todas as tentativas do advogado de aprisioná-lo em uma lógica de inclusão ou exclusão de sentidos, vale dizer, uma lógica de "ou isto ou aquilo" a ser desdobrada em ou copiar ou não, ou obedecer ou não, ou deixar ou não o escritório de Wall Street. Bartleby, por assim dizer, ocupa sempre um entre-lugar em que o que é pode ao mesmo tempo não ser e o que não é pode ser. Representante dessa lógica alternativa de suspensão de sentido, Bartleby interessa a Agamben principalmente porque representa mais um exemplo de uma "constelação filosófica" que inclui, entre outros, representantes do pensamento islâmico, da tradição filosófica dos céticos, da teologia medieval e do sistema filosófico de Leibniz. ${ }^{43}$ E é nessa companhia que Bartleby ocupa posição de destaque: é "a última, extremada figura" da tradição filosófica do "escriba que não escreve". ${ }^{44}$ Agamben percebe, nessa decisão de não escrever, um messianismo político em que a potência pura que antecede o ato que dela resulta constitui uma forma radical de resistência.

Para Agamben, no experimento de contingentia absoluta realizado por Bartleby, realiza-se o que Avicena chamara de "potência perfeita". Enquanto a "potência material" assemelha-se à de uma "criança que poderá certamente um dia aprender a escrever, mas que não sabe ainda nada da escrita", e a "potência fácil" à de "uma criança que começa a familiarizar-se com a pena e com a tinta e apenas sabe traçar as primeiras linhas", a "potência perfeita [...] é aquela de um escriba perfeitamente senhor da arte de escrever, no momento em que não escreve ('potentia scriptoris perfecti in arte sua, cum non scripserit')". ${ }^{45}$ Trata-se aqui da forma completa ou perfeita de potência porque nela não ocorre passagem para a realização em um ato. Permanece, portanto, em uma modalidade pura de ter o poder sem concretizá-lo, ou seja, na modalidade em que a

\footnotetext{
${ }^{42}$ AGAMBEN. Bartleby, ou da Contingência, p. 35.

${ }^{43}$ AGAMBEN. Bartleby, ou da Contingência, p. 8.

${ }^{44}$ ABAMBEN. Bartleby, ou da Contingência, p. 16.

${ }^{45}$ AGAMBEN. Bartleby, ou da Contingência, p. 15.
} 
potência é, ao mesmo tempo, de ser e não ser. Habitando essa dimensão de contingência absoluta que é a condição de possibilidade de todo ato concreto, do ato criativo inclusive, o Bartleby de Agamben deixa de ser o escrevente melancólico punido por Wall Street e transforma-se em um novo Messias. "Ele não vem", Agamben conclui, "como Jesus, para redimir o que aconteceu, mas para salvar o que não aconteceu". ${ }^{46} \mathrm{E}$ essa salvação do que não aconteceu, como bem observou Kevin Attel, é "uma alegoria" da teoria da potência do filósofo italiano. ${ }^{47}$

\section{Políticas da Interpretação}

Aopção por uma prática interpretativa alocrática ou pela alternativa autocrática justifica-se menos em termos de uma hermenêutica que tem por objetivo determinar a validade maior ou menor de um conhecimento do que em termos de uma política que indaga sobre a conveniência de seu uso em um contexto histórico. Em um contexto de validade hermenêutica, tanto a leitura feita por Leo Marx como a alternativa proposta por Agamben justificam-se porque fundamentam-se em códigos-mestres que nada deixam a desejar, quando aplicados ao conto, em termos de coerência lógica. Seria talvez possível propor a validade maior da leitura alocrática de Marx na medida em que o crítico norte-americano consegue cobrir (para usar o termo sugerido por Barthes) mais completamente o sistema de significados do conto. Mas a proposta cai por terra quando se lembra que a própria amplitude da cobertura textual depende do código-mestre escolhido, que delega autoridade para o discurso outro da história. Em um contexto político, por outro lado, a pergunta sobre o valor maior ou menor das leituras faz sentido porque a indagação a ser feita agora diz respeito ao uso da prática de leitura em determinada situação. Em uma sociedade em que uma comunidade interpretativa de acadêmicos e intelectuais percebe que seu trabalho deve ser, pelo menos em parte, dedicado a uma denúncia das devastações socioculturais provocadas pelo acúmulo do capital, o conto de Melville apresenta-se como uma oportunidade exemplar para o exercício crítico. Por outro

\footnotetext{
${ }^{46}$ AGAMBEN. Bartleby, ou da Contingência, p. 47.

47 "For what Agamben discerns in Bartleby's story is undoubtedly an allegory for his own potentiology" (ATTEL. Potentiality, Actuality, Constituent Power, p. 51, tradução minha).
} 
lado, em um contexto acadêmico que decide priorizar o entendimento de um novo sistema filosófico, a fórmula de Bartleby apresenta-se como exemplo maior de uma constelação de pensadores que defenderam a prioridade da potência em relação ao ato. No caso de Agamben, o mais recente representante dessa constelação, resta saber se essa priorização política da potência supostamente confirmada pela seleção mínima de detalhes do conto não poderia ter seu valor questionado não em termos hermenêuticos, mas em termos políticos. Seria então imperativo indagar sobre a possibilidade de a prioridade dada à potência trazer em seu bojo formas de quietismo que impedem a ação. São questões já introduzidas, por exemplo, pelo trabalho de Antonio Negri e Michael Hardt e que podem, dadas as limitações do presente ensaio, ser apenas apontadas como fundamento para um trabalho posterior. Será necessário então tentar entender, sistematicamente, a distinção proposta, nas duas páginas que Hardt e Negri dedicam a Bartleby em Empire, entre os conceitos de homo tantum e homohomo. Como Agamben, percebem os autores em Bartleby aquela rejeição radical da autoridade que "é o passo inicial da política de libertação". ${ }^{48}$ Mas trata-se de um início que nada vale sem os passos seguintes:

Para além da simples rejeição, ou como parte dessa rejeição, precisamos construir uma nova modalidade de vida e, sobretudo, uma nova comunidade. Esse projeto leva não em direção à vida nua do homo tantum mas em direção ao homohomo, humanidade inclusiva, enriquecida por uma inteligência coletiva e pelo amor da comunidade. ${ }^{49}$

Se Bartleby representa, para Agamben, a comunidade que vem, não estaria esta comunidade da "vida nua do homo tantum" desde sempre assombrada pela possibilidade de ser constituída por um homem só que, porque somente (tantum) homem, não pode escapar daquela solidão

\footnotetext{
48 "[...] the first step in a politics of liberation" (HARDT; NEGRI. Empire, p. 204, tradução minha).

49 "Beyond the simple refusal, or as part of that refusal, we need also to construct a new mode of life and above all a new community. This project leads not toward the naked life of homo tantum but toward homohomo, humanity squared, enriched by the collective intelligence and love of the community" (HARDT; NEGRI. Empire, p. 204, tradução minha).
} 
que o narrador do conto de Melville chama de "miserável" e que nele desperta um sentimento de "pungente e irresistível melancolia"? Surpreso ao encontrar Bartleby ocupando o escritório em um domingo, o que confirmaria a suspeita de que o escrevente tinha "feito do escritório a sua casa", o narrador escreve:

E, assim, de pronto, fui acometido de um gravíssimo pensamento: Que miserável solidão se revela aqui! Sua pobreza é imensa; mas esse isolamento, esse desamparo... que horror! Pense nisso. Aos domingos, Wall Street é tão deserta quanto Petra; e todas as noites de todos os dias é um só vazio. Este edifício também, que nos dias da semana se enche de vida e trabalho, tão logo a noite cai torna-se pura ausência, e durante o domingo resta-lhe apenas o abandono. E aqui Bartleby faz sua morada; único espectador da solidão onde antes habitava a multidão - como se fosse um inocente e transformado Mário remoendo um passado amargo sobre as ruínas de Cartago! ${ }^{51}$

\section{Referências}

AGAMBEN, Giorgio. Bartleby, ou da Contingência. Tradução de Vinícius Hoensko. Belo Horizonte: Autêntica, 2015.

AGAMBEN, Giorgio. La comunità che viene. Torino: Giulio Einaudi Editore, 1990.

ATTEL, Kevin. Potentiality, Actuality, Constituent Power. Diacritics, Baltimore, v. 39, n. 3, p. 35-53, 2009. Doi: https://doi.org/10.1353/ dia.2009.0023.

BARTHES, Roland. O que é a crítica? In: . Crítica e verdade. Tradução de Geraldo Gerson de Souza. São Paulo: Perspectiva, 1970, p 157-164.

BERKMAN, Gisèle. L'Effet Bartleby: Philosophes Lecteurs. Paris: Hermann Éditeurs, 2011.

${ }^{50}$ MELVILLE. Bartleby, o Escrevente, p. 41.

${ }^{51}$ MELVILLE. Bartleby, o Escrevente, p. 41-42. 
CULLER, Jonatham. The Pursuit of Signs. London: Routledge, 2001.

DE MAN, Paul. Blindness and Insight. Minneapolis: University of Minnesota Press, 1971.

DELEUZE, Gilles. Crítica e clínica. Tradução de Peter Pál Pelbart. São Paulo: Editora 34, 1997.

EAGLETON, Terry. After Theory. New York: Basic Books, 2003.

FORSTER, Edward Morgan. Aspects of the Novel. New York: Harcourt, Brace and Company, 1927.

HARDT, Michael; NEGRI, Antonio. Empire. Cambridge: Harvard University Press, 2000.

HIRSCH, Eric Donald. The Politics of Theories of Interpretation. Critical Inquiry, Chicago, v. 9, n. 1, p. 235-247, set. 1982. Doi: https:// doi.org/10.1086/448197.

MARX, Leo. Melville's Parable of the Walls. The Sewanee Review, Sewanee, v. 61, n. 4, p. 602-627, 1953.

MELVILLE, Herman. Bartleby, o Escrevente. Tradução de Bruno Gambarotto. São Paulo: Grua Livros, 2014.

MILLER, Joseph Hillis. Deconstructing the Deconstructers. Diacritics, Baltimore, v. 5, n. 2, p. 24-31, 1975. Doi: https://doi.org/10.2307/464639.

POE, Edgar Allan. The Man of the Crowd. In: MABBOT, Thomas Ollive (ed.). Collected Works of Edgar Allan Poe. London: Belknap Press, 1978. p. 506-518.

TALLY, Robert T. Reading the Original: Alienation, Writing, and Labor in "Bartleby, the Scrivener". In: BLOOM, Harold. Alienation. New York: Chelsea House, 2009. p. 1-10. (Bloom's Literary Themes). 